\title{
Teologia em tempos de HIV/AIDS: dilemas e proposições ${ }^{1}$
}

\author{
Theology in HIV/AIDS era: dilemmas and propositions
}

\begin{abstract}
Clélia Peretti
Doutora em Teologia pela Escola Superior de Teologia São Leopoldo, RS, Mestre em Educação pela Pontifícia Universidade Católica do Paraná (PUCPR), professora do Programa de Pós-Graduação Mestrado em Teologia - e do Bacharelado em Teologia da Pontifícia Universidade Católica do Paraná (PUCPR), Curitiba, PR - Brasil, e-mail: clelia.peretti@pucpr.br
\end{abstract}

\section{Resumo}

Este artigo propõe uma reflexão fenomenológico-teológica sobre o Vírus da Imunodeficiência Humana (HIV) e sobre a doença que ele causa, a Síndrome da Imunodeficiência Adquirida (AIDS), a partir de intervenções realizadas por agentes da Pastoral da AIDS na Arquidiocese de Curitiba e por profissionais da saúde no Grupo de Adesão ao Tratamento do HIV/AIDS do Hospital de Clínicas do Paraná (Brasil). 0 estudo faz uma análise dos dilemas que se apresentam às políticas públicas brasileiras de enfrentamento à síndrome e discute os sentidos e os significados atribuídos à vivência da soropositividade nas suas dimensões pessoal e comunitária. Aborda as distintas faces

1 Esse artigo foi apresentado na Tenth Biannual Conference - IAPT - International Academy of Practical Theology. City of Desires A place for God? Amsterdam, July 21-25, 2011, com o título: Theology in times of HIV/AIDS: dilemmas and propositions. 
do HIV/AIDS, a feminização, a juvenização, a pauperização, a interiorização, seus reflexos no cenário brasileiro e a necessidade de um conceito de saúde voltado para a pessoa humana na sua totalidade e não somente para suas patologias. O fenômeno HIV/ AIDS é compreendido na sua dimensão ontoteológica, o que possibilita uma reflexão sobre o cuidado (cura) integral. Apresenta uma Teologia em movimento, preocupada com a reconstrução da pessoa humana a partir da sua imanência e transcendência. A Teologia aqui proposta tem seu fundamento bíblico-teolológico no Evangelho de João. $\mathrm{Na}$ imagem joanina do "Deus vivo e verdadeiro" (Jo, 6:57), fundamentamos a nova geração da pessoa humana acometida pela soropositividade.

Palavras-chave: Teologia. Políticas públicas. Saúde. Cuidado. HIV/AIDS.

\section{Abstract}

This article proposes a phenomenological-theological reflection on the Human Immunodeficiency Virus (HIV) and the disease it causes, the Acquired Immune Deficiency Syndrome (AIDS), considering interventions by the workers in Pastoral da AIDS of the Archdiocese of Curitiba city and by healthcare professionals in the Adherence Treatment Group of HIV/AIDS of the Clinical Hospital of Paraná (Brazil). The study is an analysis of the dilemmas the Brazilian public policies undergo when facing the syndrome and it discusses the senses and meanings attributed to the experience of seropositivity in its personal and communitary dimensions. It addresses the different features of HIV/AIDS, the feminization, the increase of diseased young people, the impoverishment, the spread from urban centers to the countryside, its reflexes in the Brazilian scenario and the need for a concept of health focused on the human person in her completude, and not just on her pathologies. The HIV/AIDS phenomenon is understood in its onto-theological dimension, which allows for a reflection on the integral care (cure). This work presents a view of a kind Theology on the move, worried with the reconstruction of the human person based on her immanence and transcendence. Theology proposed here has its biblical foundation in the Gospel of John. On the Johannine image of the "true and living God" (Jn 6.57), it is based on the discussion of the new generation of people affected by seropositivity.

Keywords: Theology. Public policies. Health. Care. HIV/AIDS. 


\section{Introdução}

Este estudo tem como ponto de partida a contribuição da fenomenologia para uma análise do significado do fenômeno HIV/AIDS no Brasil e, especialmente, na cidade de Curitiba (Paraná). Insere-se no projeto de pesquisa Teologia HIV/AIDS e Gênero, do Programa de Pós-Graduação em Teologia - Mestrado - da Pontifícia Universidade Católica do Paraná (PUCPR).

Enquanto nos anos 1980 as pesquisas sobre a Síndrome da Imunodeficiência Adquirida (AIDS) preocupavam-se principalmente com a descoberta do Vírus da Imunodeficiência Humana (HIV) e suas formas de transmissão, hoje estudos realizados por pesquisadores de diferentes áreas do saber têm revelado que a temática da AIDS ultrapassa a dimensão biotecnológica. ${ }^{2}$

A AIDS se inscreve em um universo específico de percepções e representações sociais que fazem com que o fenômeno e o risco de infecção sejam compreendidos das mais diversas maneiras. As pesquisas mostram que o HIV, organismo que infecta o corpo, pode levar o sujeito a desenvolver a síndrome da AIDS, mas este é apenas um dos modos para se compreender tal fenômeno, que se constitui numa "rede de significados" pela qual os sujeitos podem reconhecer suas ações (GEERTZ, 1989).

\footnotetext{
2 Para maiores informações sobre a temática, consultar: PARKER, R.; HERDT, G.; CARBALLO, M. Cultura sexual, transmissão do HIV e pesquisas sobre AIDS. In: CZERESNIA, D. et al. (Org.). AIDS: pesquisa social e educação. São Paulo: Hucitec; Rio de Janeiro: ABRASCO, 1995. p. 17-45; PARKER, R. Na contramão da AIDS: sexualidade, intervenção, política. Rio de Janeiro: ABIA; Editora 34, 2000; PAIVA, V. 0 simbolismo da AIDS, alteridade e cidadania. In: PAIVA, V. (Org.). Em tempos de AIDS: viva a vida: sexo seguro, prevenção, drogas, adolescentes, mulheres, apoio psicológico aos portadores. São Paulo: Summus, 1992. p. 53-62; MARTIN, D. Mulheres e AIDS: uma abordagem antropológica. Revista USP, n. 33, p. 89-101, 1997; TURA, L. F. R. A AIDS, o preservativo e a prevenção". In: JORNADA INTERNACIONAL SOBRE REPRESENTAÇÕES SOCIAIS: TEORIA E CAMPO DE APLICAÇÃO, 1., 1998, Natal. Anais... Natal: Jornada Internacional sobre Representações Sociais: Teoria e Campo de Aplicação, 1998. p. 38; MADEIRA, M. C. A confiança afrontada: representações sociais da AIDS para jovens. In: MADEIRA, M.; JODELET, D. (Org.). AIDS e Representações sociais: à busca de sentidos. Natal: EDUFRN, 1998. p. 47-72; MONTEIRO, S. S. AIDS e proteção: a visão de jovens de um bairro popular. Revista de Estudos Feministas, ano 7, p. 72-88, 1999a; MONTEIRO, S. S. AIDS, sexualidade e gênero: a lógica da proteção entre jovens de um Bairro Popular Carioca. 1999. 186 f. Tese (Doutorado em Saúde Pública) Escola Nacional de Saúde Pública, FIOCRUZ, Rio de Janeiro, 1999b.
} 
É partindo desse pressuposto que a perspectiva fenomenológico-teológica de Edith Stein nos auxilia a compreender as experiências vividas em relação ao fenômeno da AIDS em sua multiplicidade de significados (PERETTI, 1997, 2009). Nesse contexto, a fenomenologia se apresenta como um método que possibilita a compreensão das dicotomias existentes entre a "exterioridade e a interioridade" da pessoa humana (MERLEAU-PONTY, 1990, p. 156). Trata-se de uma pesquisa qualitativo-descritiva, um modo trinitário de considerar e analisar a pessoa humana em suas dimensões corpórea, psíquica e espiritual, que, nesse caso, se mostra com a enfermidade do HIV/AIDS (ALES BELLO, 2000; STEIN, 1999). $\mathrm{Na}$ concepção de Edith Stein, a pessoa humana, em sua estrutura única, essencial, universal, não pode ser reduzida ao fenômeno HIV/AIDS. Por ser livre, na vivência do cuidado (cura), ela se revela capaz de transcender a sua história pessoal, atribuindo um sentido próprio, originário, ontológico, ao acontecimento de sua existência na comunidade, impossível de ser totalmente desvirtuada.

Na sua dimensão comunitária, a pessoa com HIV/AIDS clama por uma Teologia Contemporânea que "volte o seu olhar" para a especificidade de sua existência. Do ponto de vista existencial, o cuidado se encontra na raiz primeira da pessoa humana, antes de só nas atitudes e situações, o que sempre significa dizer que também se encontra em toda atitude e situação de fato; possui uma dimensão ontológica que entra na constituição do ser humano. Nesse sentido, diz Martin Heidegger em Ser e Tempo:

certa vez, atravessando um rio, "Cura" viu um pedaço de terra argilosa: cogitando, tomou um pedaço e começou a lhe dar uma forma. Enquanto refletia sobre o que criara, interveio Júpiter. A cura pediu-lhe que desse espírito à forma de argila, o que ele fez de bom grado. Como a cura quis então dar seu nome ao que tinha dado forma, Júpiter a proibiu e exigiu que fosse dado o nome. Então "Cura" e Júpiter disputavam sobre o nome, surgiu também a terra (tellus) querendo dar o seu nome, uma vez que havia fornecido um pedaço de seu corpo. Os dois disputantes tomaram Saturno como árbitro. Saturno pronunciou a seguinte decisão, aparentemente equitativa: "Tu, Júpiter, por teres dado o espírito, deves receber na morte o espírito e tu, terra, por teres dado o corpo, deves receber o corpo. Como, 
porém, foi a 'cura' quem primeiro o formou, ele deve pertencer à 'cura' enquanto viver. Como, no entanto, sobre o nome há disputa, ele deve se chamar 'homo', pois feito de húmus (terra)” (HEIDEGGER, 1989, p. 263).

Intervenções realizadas por agentes da Pastoral da AIDS na Arquidiocese de Curitiba e por profissionais da saúde no Grupo de Adesão ao Tratamento do HIV/AIDS do Hospital de Clínicas do Paraná (Brasil) revelam, em vivências de pessoas em estado de anomia(as) ou em situações de fragilidade humana, uma intensa busca religiosa. Para o teólogo brasileiro Rubens Alves, a busca religiosa tem relação com o projeto existencial da pessoa humana, na qual as questões de vida e de morte têm um lugar preponderante (ALVES, 1984).

Em vista do exposto, este artigo propõe em tempos de HIV/AIDS uma Teologia, germinada do solo do cuidado, que "se volte" à pessoa humana e adentre o mistério de sua existência, educando-a para um contínuo transcender-se na comunidade. No que diz respeito à Teologia com os outros saberes, a centralidade do cuidado não é a razão, mas o pathos, o "entropathos", isto é, a capacidade de o teólogo sentir e acolher o sofrimento do "outro" com HIV/AIDS. Sem esse cuidado, a pessoa deixa de ser "humana”.

\section{Dilemas nas políticas da saúde diante do fenômeno da AIDS}

Historicamente, o HIV e a AIDS trouxeram consigo uma série de fatos morais, novos, relacionados as suas características epidemiológicas, clínicas e sociais. O que mais se preconiza hoje em dia são dilemas morais. Concomitantemente, preconizam-se cuidados universais de proteção, humanização da assistência e respeito à individualidade, à liberdade e à privacidade das pessoas que vivem com essa enfermidade. $\mathrm{O}$ fenômeno da AIDS se apresenta, assim, como um típico exemplo da tensão entre obrigações e direitos individuais dessas pessoas que clamam por cuidados (cura) e proteção da Saúde Pública.

Embora tenham surgido no Brasil importantes pontos de convergência entre as diferentes experiências de implantação de políticas públicas, faz-se necessária uma integração entre os avanços e as condições 
sociais e de qualidade de vida das pessoas com HIV/AIDS, evidenciando questões complexas como a sexualidade, o enfrentamento do estigma e da discriminação que permeiam a vida social e familiar e o tratamento medicamentoso. Não basta, no entanto, a geração de novos conhecimentos e tecnologias. É preciso, antes, que o sistema de saúde se reestruture para efetivamente incorporá-los.

Nesse sentido, como se verá a seguir, é preciso rediscutir o conceito de saúde apresentado pela Organização Mundial de Saúde (OMS) em 1948, que a definia como um completo estado de bem-estar físico, mental e social e não meramente a ausência de doença. De acordo com Faria e Vaz (1995, p. 101): "A AIDS nos deixa a dúvida crucial sobre nosso conceito do que são as doenças e qual sua origem. [...] Quanto mais acumulamos informações sobre a doença, mais rapidamente nossas convicções sobre o assunto se esvanecem".

Para tanto, o conceito de saúde da OMS tem se mostrado insuficiente na atuação do teólogo, que se depara na cotidianidade com o fenômeno do HIV/AIDS, manifestado em um número de pessoas humanas infectadas e doentes que têm aumentado significativamente. Por HIV, compreendemos um retrovírus que causa no organismo da pessoa humana disfunção imunológica crônica e progressiva graças ao declínio dos níveis de linfócitos CD4+; quanto mais baixo for o índice destes, maior é o risco de o indivíduo desenvolver AIDS (CALVETTI, 2010). Na concepção de Calvetti, o período entre a infecção do HIV e a manifestação da doença pode durar alguns anos. Apesar de a pessoa humana infectada com esse vírus se mostrar, em muitos casos, assintomática, pode apresentar importantes transtornos na esfera psicossocial a partir do momento do diagnóstico (CALVETTI, 2010).

No que diz respeito à dimensão psíquica das pessoas humanas com HIV/AIDS, estudos atuais revelam que as diversas alterações que podem ocorrer no sistema nervoso central, associadas à depressão e ao estresse, podem influenciar a evolução da enfermidade. As alterações psicológicas mais significativas que a pessoa humana infectada vivencia, em diversos momentos de sua vida - desde quando se depara com o resultado da soropositividade até as últimas fases da doença - são: ansiedade, depressão, ira, culpa, revolta, obsessões e auto-observação, além de excessiva 
preocupação com a saúde e possível aumento da vulnerabilidade biológica que tais alterações podem causar (CALVETTI, 2010). A pessoa humana com essa enfermidade tende a apresentar incertezas, que geram ansiedade, insegurança e medo.

A Pastoral da AIDS, da Arquidiocese de Curitiba, e o Grupo de Adesão ao Tratamento do HIV/AIDS do Hospital de Clínicas do Paraná, deparam-se, constantemente, com estados depressivos de humor associados à presença de crenças negativas sobre a enfermidade e sentimentos de desesperança, que levam a pessoa a se sentir desmotivada no que tange à dimensão do cuidado (cura) de sua própria saúde e a não confiar em suas habilidades para lidar com as exigências do tratamento.

As manifestações de ansiedade (sensação de insegurança física, apreensão, temor ou ameaça, inquietação, palpitações e, em alguns casos, perda de sono e memória) podem ocorrer em algumas situações específicas, tais como: medo de ter contaminado parceiros e/ou filhos; receio da revelação do diagnóstico e de rejeições implícitas e explícitas; mudanças do esquema terapêutico, por falência ou intolerância; variação nas contagens de linfócitos $\mathrm{CD} 4+$ e na carga viral, além das dificuldades ligadas à prática de sexo seguro (BRASIL, 2008). Concomitantemente, é observado, também, que os soropositivos possuem dificuldade em enfrentar a discriminação social, além de medo de adoecerem gravemente e de depararem-se com o fenômeno da grande travessia: a morte.

No que diz respeito ao estresse, um nível mantido no tempo com forte intensidade, e/ou com alta frequência, pode levar ao desequilíbrio de diversos sistemas ou órgãos (ULLA; REMOR, 2002). O alto nível de estresse, na maioria dos casos, leva o organismo da pessoa humana a manter uma ativação acima de suas possibilidades e dá lugar a um desgaste excessivo com possíveis alterações ou deterioração no funcionamento dos órgãos ou sistemas-alvo.

Outra reação psicológica à infecção do HIV, que afeta muitas pessoas, é a depressão (falta de sentido existencial) que, com o estresse, pode diminuir o número de linfócitos $C D 4+$ e piorar o estado de saúde das pessoas que vivem com a doença (BAYÉS, 1994).

$\mathrm{O}$ advento dos antiretrovirais tem propiciado aumento no tempo de sobrevida. Contudo o seu alto custo e os inúmeros efeitos colaterais 
associados à inexistência de cura, à toxicidade das drogas e à necessidade de elevada adesão ao tratamento constituem-se em barreiras ao sucesso prolongado da terapia (BRASIL, 2006). Portanto, a adesão ao tratamento antiretroviral pode estar associada ao modo como a pessoa enferma vivencia a sua sexualidade, seus hábitos, suas relações sociais e o seu ser patológico. Nesse caso, o ato de aderir ao tratamento medicamentoso se revela como tentativa de inibir e retardar a degradação sofrida pelo vírus e controlar a carga viral. A eficiência do tratamento possibilita à pessoa viver por um tempo mais prolongado, sem a manifestação de doenças oportunistas da AIDS, como tuberculose, herpes genital, entre outras patologias (KERN, 2004).

A partir da década de 1990, novos tratamentos e medicamentos foram desenvolvidos para a prevenção ou cura das doenças associadas à AIDS. No entanto tais tratamentos não conseguem a cura dessa enfermidade. Pesquisas se orientam em torno da investigação das associações entre variáveis psicológicas - enfrentamento, suporte social e a percepção da qualidade de vida -, buscando identificar fatores que propiciam o ajustamento à condição de enfermidade crônica e a consideração real da disponibilidade de tratamento (CALVETTI, 2010). Também são contempladas novas possibilidades de prevenção, como a vacina e as microbicidas. No horizonte, surge uma esperança: o desenvolvimento da vacina para o HIV, que constitui um grande desafio para o século XXI.

Estatisticamente, cerca de 33,4 milhões de pessoas no mundo convivem com a infecção do HIV, e as mulheres representam a metade dessa população (BRASIL, 2011, p. 4). Esse fenômeno nos impõe questões éticas imprescindíveis para preservar a pessoa humana nas suas dimensões corpórea, psíquica e espiritual. Não se pode esquecer que a intersubjetividade se constitui em um mundo compartilhado por todos. A pessoa vivencia a existência e a humanidade no outro e em si mesmo. De tudo o que a pessoa humana participa, ela faz experiência de si. Quer se trate no mundo interior ou no mundo exterior, o ser humano sempre procura algo que o leve a superar a si mesmo, que o ajude a transcender a sua experiência no mundo. Em Teologia, em tempos de HIV/AIDS, essas estatísticas interrogam: O dito HIV/AIDS contempla a pessoa humana na sua totalidade? 
Em cada cultura, vive-se a enfermidade de maneira diferente. A enfermidade não é só um fato biológico. É do mesmo modo uma vivência que o enfermo sofre e interpreta de acordo com sua cultura. Do ponto de vista histórico, a cura integral do ser humano sempre foi objeto de reflexão da humanidade. De fato, a medicina grega, criada por Hipócrates (450-350 a.C.), não invocava o poder curador dos deuses, conforme Asclépio (dos gregos) ou Esculápio (dos latinos), mas, com base em teorias anatômicas, destacava a enfermidade, diagnosticava as suas causas e buscava algum remédio que ajudasse a recuperar o equilíbrio do corpo (PAGOLA, 2010).

Na vivência cristã originária, a esperança de libertação de enfermidades sempre esteve presente nas pessoas, a fim de desfrutarem uma vida sadia. Isso revela, então, que o "cuidado como modo de ser" perpassa toda existência humana, possui ressonâncias nas dimensões de transcendência e imanência, e busca equilíbrio e coexistência (BOFF, 1999).

Pensando desse modo, uma Teologia do Cuidado em tempos de HIV/ AIDS exige uma prática teológica, interdisciplinar e transdisciplinar, que aponte um encontro decisivo da pessoa enferma com Jesus - o curador. Nos Evangelhos, Jesus é apresentado como alguém que contagia saúde e vida; Ele se compadece das pessoas: literalmente, "se lhe comovem as entranhas" (Mc 1, 41; 9, 22; Mt 9, 36; 14,14; 15, 32; 20, 4; Lc 7, 13).

A terapia que Ele propõe é sua própria pessoa: seu amor apaixonado à vida, sua acolhida afetuosa a cada enfermo ou enferma, sua força para regenerar a pessoa a partir de suas raízes, sua capacidade de transmitir sua fé na bondade de Deus em funcionamento. Seu poder de despertar energias desconhecidas no ser humano criava as condições que tornavam possível a recuperação da saúde (PAGOLA, 2010, p. 202).

Por fim, resta dizermos, então, que a ação sanadora de Jesus vai além da eliminação do problema orgânico. A cura do organismo fica englobada numa cura mais integral da pessoa humana, que é reconstruída a partir de sua história pessoal e reconciliada com a comunidade, esta concebida como locus de respeito à liberdade. É um acontecimento totalmente humano que possui seu fundamento na estrutura pela qual a pessoa é constituída. 


\section{As expressões da AIDS no Brasil}

No Brasil, diversos atores sociais - instâncias federais, estatais, órgãos internacionais do sistema das Nações Unidas (ONU), movimentos sociais, organizações não governamentais (ONGs), instituições religiosas, empresas públicas e privadas, entre outras agremiações - vêm se sensibilizando com a epidemia de AIDS. Há intervenções políticas, sociais e religiosas tanto no que diz respeito à prevenção quanto ao atendimento ao soropositivo.

Especialistas têm destacado o Brasil como uma referência latino-americana pelo compromisso político de acesso universal aos remédios antirretrovirais. O Programa Nacional DST e AIDS beneficia 180 mil pessoas soropositivas, que recebem gratuitamente o coquetel de remédios. Uma das singularidades a mais na luta contra a AIDS foi a quebra de patentes, o que permitiu que $80 \%$ dos antirretrovirais consumidos pelos brasileiros fossem produzidos no país. Embora já tenha sido aplicada uma grande quantidade de recursos financeiros, reconhece-se que ainda é preciso fazer um esforço maior focado em prevenção.

Pesquisas recentes publicadas no Boletim Epidemiológico - AIDS e DST, do Ministério da Saúde, trazem os seguintes dados sobre a prevalência de infecção do HIV no Brasil:

0,6\% na população de 15 a 49 anos de idade ( $0,4 \%$ nas mulheres e $0,8 \%$ nos homens), 0,12\% nos jovens do sexo masculino de 17 a 20 anos de idade e $0,28 \%$ em mulheres jovens de 15 a 24 anos. Nas populações vulneráveis, as prevalências são mais elevadas e destacam-se aquelas entre usuários de drogas ilícitas (5,9\%), homens que fazem sexo com homens $(10,5 \%)$ e mulheres profissionais do sexo (5,1\%) (BRASIL, 2010b, p. 6).

Essa mesma fonte revela que a pandemia da AIDS está mudando seu perfil, atingindo cada vez mais as populações vulnerabilizadas socialmente e sendo caracterizada por quatros faces distintas: feminização, juvenização, pauperização e interiorização.

A primeira face da pandemia chamada de feminização encontra-se no crescente número de mulheres infectadas pelo HIV. Observando os dados do Boletim Epidemológico do Departamento de AIDS/DST (2010), 
nota-se que o número de casos da AIDS é maior entre os homens do que entre as mulheres. Contudo, ao longo do tempo, a razão entre sexos (número de casos de homens dividido pelo número de casos em mulheres) vem diminuindo de forma progressiva. Em 1989, a razão de sexo era de cerca de 6 casos de AIDS no sexo masculino para cada 1 caso no sexo feminino. Em 2009, chegou a 1,6 casos em homens para cada 1 caso em mulheres, sendo que a taxa de incidência por 100.000 habitantes, em 2008, foi de 19,8 e, em 2009, de 20,1.

A segunda face da pandemia é conhecida como juvenilização. Depara-se com uma população jovem que desconhece o mundo antes da AIDS e se infecta principalmente por meio das relações sexuais. Milhões desses jovens já morreram e, no entanto, a epidemia do HIV/AIDS na faixa etária entre 13 a 24 anos consiste no maior número de pessoas contaminadas, apesar de, em grande parte, continuarem invisíveis aos olhos dos adultos e dos próprios jovens. É importante ressaltar, ainda, que, nesse segmento, ${ }^{3}$ os jovens são responsáveis por $11,3 \%$ (66.751) dos casos acumulados no país desde 1980 até junho de 2010. A distribuição, segundo as regiões, em 2009, descortina que a maior proporção dos casos nessa fase de desenvolvimento humano, em ambos os sexos, está atribuída à categoria de exposição sexual, sendo $73,8 \%$ no sexo masculino e $94,0 \%$ no sexo feminino (BRASIL, 2010b, p. 6).

$\mathrm{Na}$ faixa etária de 13 a 19 anos, o número é de 12.693, e para a faixa etária de 20 a 24 anos, é de 54.058 casos de AIDS. Na primeira ocorrência, o número de casos é maior entre as mulheres. São 10 casos notificados em mulheres para 8 casos em homens. Essa realidade se relaciona, de acordo com as pesquisas realizadas pelo Ministério da Saúde (2010), com a tendência de aumento desigual da AIDS entre os adolescentes de sexo

3 "No ano de 2009, foram identificados, no banco relacionado, 3.398 casos de AIDS em jovens de 13 a 24 anos de idade; a taxa de detecção foi de 8,3 casos por 100.000 habitantes [...], sendo 1.875 casos no sexo masculino (9,1/100.000 habitantes) e 1.523 no feminino (7,5/100.000 habitantes). A razão de sexos, que era de 3,7:1 (37 homens para cada 10 mulheres) em 1990, caiu para 1,1:1 (11 homens para cada 10 mulheres) em 1998, culminando com a inversão dessa razão no ano 2000 (0,9:1 - 9 homens para cada 10 mulheres). Entretanto, entre 2007 e 2009, os jovens do sexo masculino voltam a ter maior participação nos casos de AIDS [...]". BRASIL. MINISTÉRIO DA SAÚDE. Semanas epidemiológicas janeiro a junho. Boletim Epidemiológico - AIDS e DST, ano VII, n. 1 2010b. Disponível em: <http://www.aids.gov.br/pagina/aids-nobrasil>. Acesso em: 20 jun. 2011. p. 6. 
feminino. Além disso, é observada maior incidência de AIDS igualmente entre os 40 a 49 anos de idade. É verificado, ao mesmo tempo, um aumento significativo dos casos de AIDS nas pessoas acima de 60 anos de idade, "que passaram de 394 casos em 1999 para 938 casos em 2009 no sexo masculino, e, no feminino, de 191 casos em 1999 para 685 casos em 2009" (BRASIL, 2010b, p. 8). Mas a faixa etária com maior deteç̧ão no país é de 35 a 39 anos, registrando-se 46,7 casos por 100.000 habitantes em 2009. No sexo masculino, a maior proporção de casos é entre jovens gays: $26,8 \%$ homossexuais e $10,2 \%$ bissexuais. ${ }^{4}$

No que tange à terceira face da AIDS, a pauperização, é observada uma intrínseca relação com a escolaridade e a renda das pessoas atingidas. E mais: de acordo com dados estatísticos da OMS (2011), as populações tradicionalmente marginalizadas estão mais vulneráveis à infecção do HIV. No caso da pauperização, as pessoas, marginalizadas, encontram dificuldades de acesso aos serviços básicos de saúde e à informação de modo específico, dificultando, sobretudo, ações de prevenção e diagnóstico precoce da doença. Outro problema relacionado à pauperização é o da discriminação e da exclusão do idoso. $O$ aumento da contaminação, nesse segmento populacional, deve-se à crescente expectativa de vida da população, melhoria geral das condições de saúde, mudanças dos padrões de doença, redução dos índices de mortalidade e diminuição da taxa de natalidade (MOTTA, 2003; SILVA, 1996).

As pessoas estão vivendo cada vez mais, despertando questionamentos sobre o modo como se percebe o processo de envelhecer e trazendo transformações nos valores éticos, estéticos e sociais. A sexualidade passa a ser comercializada pela mídia sob forma de medicamentos, terapias miraculosas, entre outros meios. $\mathrm{O}$ uso de terapias hormonais e a descoberta do Viagra possibilitaram uma melhor qualidade de vida sexual para esse segmento. O preservativo, para esse grupo etário, é um artefato pouco utilizado ao longo de suas vidas e uma ferramenta meramente

\footnotetext{
4 " $(63,6 \%)$ relaciona-se à categoria de exposição sexual, distribuídos entre heterossexual (31,2\%), homossexual (20,6\%) e bissexual (11,8\%), e, na categoria de exposição sanguínea, o uso de drogas injetáveis pode ser observado em $17,6 \%$ dos casos. No sexo feminino, os casos de AIDS estão relacionados majoritariamente (91,2\%) à categoria de exposição heterossexual" (BRASIL, 2010b, p. 9).
}

Rev. Pistis Prax., Teol. Pastor., Curitiba, v. 4, n. 1, p. 63-86, jan./jun. 2012 
anticonceptiva que apresenta dificuldade técnica na sua utilização. Alia-se a esses elementos a dificuldade de o idoso quebrar seus tabus e mitos sobre a sexualidade. O silêncio em relação à soropositividade, além dos sentimentos destrutivos, torna o cotidiano comprometido pela instabilidade emocional e pela grande sensibilidade às vicissitudes desse convívio. O preconceito é, ainda, um dos maiores obstáculos à prevenção da doença em pessoas idosas.

A quarta face é a interiorização da AIDS nas diferentes regiões do Brasil. A doença está saindo dos centros urbanos, onde as campanhas de prevenção são mais expressivas, e o tratamento médico atinge maior número de cidadãos. Nos últimos anos, a propagação da AIDS no Brasil revela uma epidemia de múltiplas dimensões que vem sofrendo extensas transformações na sua evolução e distribuição social. Na década de 1980, partindo do eixo Rio de Janeiro-São Paulo, os casos de AIDS se disseminaram para as demais regiões como Porto Alegre, Recife, Curitiba, Belo Horizonte e Salvador.

Segundo dados do Boletim Epidemiológico,

a distribuição dos casos da AIDS, em 2009, mostra que 38,2\% dos casos encontram-se na Região Sudeste, seguida do Nordeste (21,9\%), Sul (21,1\%), Norte $(11,1 \%)$ e Centro-Oeste (7,7\%). Embora a Região Sudeste apresente maior número de casos em 2009, o Sul destaca-se com a maior taxa de deteç̧ão nesse ano, 12,6/100.000 habitantes (BRASIL, 2010b, p. 7).

Apesar do trabalho de conscientização e de repetidas campanhas, o cenário da AIDS nos municípios menores, segundo o especialista da Saúde Pública Alccy Martins, em entrevista ao Jornal da Globo, no dia 17 de junho de 2011:

são, em média, 355 novos casos da doença, em Fortaleza, por ano. A capital cearense está entre os 15 municípios brasileiros com maiores aumentos. Em último lugar, ficou Salvador, com índice de $41 \%$. Ananindeua, no Pará, primeiro no ranking dos piores, marcou 380\%. São Luís, no Maranhão, também tem muito a fazer contra o avanço da doença. Lá, foram 272,1\% de aumento de novos casos. No lado positivo dos municípios com maiores quedas nos índices, São Paulo dá exemplo, com redução de $45 \%$. Outra capital que conseguiu redução foi Curitiba, contabilizando 
menos 34,4\%. Ribeirão Preto (SP) também tem o que comemorar: é o primeiro na lista dos melhores, queda de $72,5 \%$ nos casos. Como posso falar de controle se Fortaleza-CE, por exemplo, tem 2 milhões de habitantes e registra 5.510 casos. Isso significa que existem 363 pessoas contaminadas para cada habitante ou melhor explicando para cada indivíduo sadio tem-se 363 pessoas querendo ou atrás de contaminá-la(o). Não posso chamar isso de controle epidemiológico (GLOBO, 2011).

De acordo com os dados do Boletim Epidemiológico (BRASIL, 2010a), a disseminação da doença, que hoje atinge 506 mil brasileiros entre os 630 mil infectados pelo vírus, tem fortes impactos na comunidade e na vida das pessoas. Ao contrair o vírus, a morte é associada à pessoa infectada, de modo que sua cidadania começa a desaparecer. Fragilizadas, essas pessoas se deparam com uma série de perdas: demissão do emprego, mudanças estéticas, dependência, proibição de frequentar determinados lugares, desprezo, omissão no atendimento médico e o abandono da família e de amigos, passando a ser descartada pela sociedade. A essas consequências sociais se incorporam, concomitantemente, o estigma, a violação de direitos e as políticas punitivas ou equivocadas para grupos de populações mais afetados pelo HIV. Nesse contexto de discriminação, a pessoa humana, com sua dignidade, é violada.

Nesse cenário, uma Teologia em Tempos de HIV/AIDS não se furta de um debate/atuação sobre os direitos humanos compreendido como espaço de garantia da liberdade. Insere-se, então, a rediscussão da sexualidade, abordada sem preconceitos e/ou crenças, com responsabilidade, por teólogos e profissionais da saúde, que põem no centro de seu agir a pessoa humana com HIV/AIDS, e não a patologia.

\section{0 impacto da epidemia do HIV/AIDS em Curitiba}

Desde 1984, data do surgimento do HIV, inúmeras iniciativas vêm sendo implementadas em Curitiba por entidades públicas e particulares para deterem a epidemia do HIV/AIDS e seu impacto na população. Na capital do Paraná, a política de combate à disseminação do HIV e da AIDS se 
insere no marco das diretrizes que regem o Sistema Único de Saúde (SUS). Ao longo desses anos de epidemia, as ações programáticas do SUS mostram-se sustentáveis e renovadas de acordo com a dinâmica epidemiológica e social da AIDS, inovando e ampliando a atenção integral e universal às pessoas afetadas pela epidemia. Vê-se uma significativa circulação de informações sobre as DSTs e muitos atores sociais e espaços se apropriarem do debate - poder público, família, escola, mídia e organizações não governamentais. Não obstante esses avanços, depara-se com um quadro preocupante em relação à infecção do HIV por adolescentes e por jovens.

De acordo com a médica Eliane Regina da Veiga Chomatas, da Secretária Municipal da Saúde, da Prefeitura Municipal de Curitiba,

[...] desde que a epidemia de HIV/AIDS começou a ser acompanhada em Curitiba, em 1984, foram diagnosticados 11 mil casos. O dado é de novembro de 2010. Cerca de 1,5 mil pessoas pertencem à faixa etária de 14-24 anos, entre as quais aproximadamente 19\% são mulheres [...]. Em 2010, em Curitiba, 61 pessoas foram diagnosticadas [nesta] faixa etária, sendo 25 mulheres (CURITIBA, 2011).

Dados do Plano de Enfrentamento da Feminização da AIDS no Estado do Paraná, de 2009, revelam que a faixa etária de 13 a 19 anos é a mais atingida, com a inversão da razão entre os sexos, apresentando 1,2 mulheres para cada homem notificado. O principal desafio social e programático da Secretaria Estadual de Saúde

é traduzir as soluções para a superação dos diferentes contextos de vulnerabilidade das mulheres às DST e HIV/AIDS em ações concretas, que assegurem o acesso aos métodos de prevenção disponíveis nos sistemas de saúde, e no caso de exposição a um determinado agravo, tenham a garantia de assistência de qualidade (PARANÁ, 2009, p. 7).

Isso é de suma importância para o presente estudo porque há uma convergência de fatores que configuram os contextos de vulnerabilidade das mulheres, gerando desafios para uma resposta integrada e intersetorial para o enfrentamento da epidemia. Tais fatores são: violência doméstica e sexual, estigma e violação dos direitos humanos, não reconhecimento das adolescentes e jovens como sujeitos de direitos, racismo e 
desigualdades étnico-raciais, pobreza e outras desigualdades socioeconômicas e uso abusivo de drogas.

Entre os fatores determinantes para a ampliação do HIV na população feminina, além da vulnerabilidade gerada pela cultura machista, que oprime a livre expressão da sexualidade da mulher, encontra-se o menor poder de negociação das mulheres quanto ao uso do preservativo e as decisões que envolvem a sua vida sexual e reprodutiva. A Pesquisa de Conhecimentos, Atitudes e Práticas da População brasileira de 15 a 64 anos de idade, realizada em 2008 pelo Ministério da Saúde,

constatou ainda que quase metade da população $(45,7 \%)$ faz uso consistente do preservativo com seus parceiros casuais (usou em todas as relações eventuais nos últimos 12 meses). As principais diferenças estão entre homens e mulheres e por faixa etária. Homens usam mais preservativos que as mulheres em todas as situações. Os jovens são os que mais fazem sexo protegido em relação aos mais velhos [...]. A análise dos dados com recorte de região e de escolaridade não mostra diferenças significativas (BRASIL, 2009).

Embora a maioria das/dos adolescentes e jovens tenha informações sobre o uso dos preservativos como a melhor maneira para evitar a infecção do HIV pela relação sexual, o percentual de uso do preservativo em todas as relações é baixo - nas relações casuais, de 49,6\%, e com parceiros fixos, de 30,7\% (BRASIL, 2009). Dados dessa mesma pesquisa de 2008, comparados com os de 2004, preocuparam o Ministério da Saúde pelas seguintes razões:

o brasileiro tem feito mais sexo casual. Em 2004, 4\% das pessoas haviam tido mais de cinco parceiros casuais no ano anterior. Em 2008, esse índice foi mais que o dobro, passando para 9,3\%. Ao lado disso, o conhecimento sobre os riscos de se infectar com o HIV e sobre as formas de prevenção continuam altos. Mesmo assim, a pesquisa identificou uma tendência na queda no uso do preservativo. Passou de $51,6 \%$ em todas as parcerias eventuais, em 2004, para 46,5\% em 2008 (BRASIL, 2009).

No que diz respeito à presença do preservativo na vida sexual das/ dos adolescentes e jovens, embora o uso pela faixa etária de 15 a 24 anos 
seja crescente na primeira relação sexual (2004, 53,2\%; 2008, 60,9\%), nas relações sexuais seguintes o uso do preservativo cai vertiginosamente. As razões para o não uso do preservativo nesse segmento estão intrinsecamente ligadas a questões educativas, religiosas e morais. Nesse ínterim, delineia-se o despreparo para lidar com a sexualidade, a cultura machista e a dificuldade de a mulher impor suas vontades, a ideia de quebra de sigilo, a sensação de estar-se imune às doenças, a não apropriação do cuidado com a própria vida e a deficiente percepção do risco de contágio graças aos avanços dos tratamentos.

Em vista do exposto, as ações de prevenção, discursos e debates precisam ultrapassar os vieses político, econômico e técnico, apoiados em práticas higienísticas que visam ao controle da dinâmica das populações. Epidemiologicamente, o HIV/AIDS não é um surto que pode ser tratado como outras doenças. A AIDS, mais do que um fato social, é um fenômeno a ser compreendido na sua dimensão ontoteológica, já que atinge o grande acontecimento da existência humana.

\section{Por uma teologia que cuida...}

Retomar a Teologia em tempos de HIV/AIDS não significa conceber e fazer uma teologia que discute apenas uma possibilidade de melhoria física. Sua ação sanadora quer ir além da eliminação de um problema orgânico. Em sentido teológico, o cuidado do organismo fica englobado num cuidado mais integral da pessoa humana. Partindo do exemplo de Jesus, que "percorria toda a Galileia, ensinando em suas sinagogas, pregando o Evangelho do Reino e curando toda e qualquer doença ou enfermidade do povo" (Mt 4,23), aspiramos à reconstrução da pessoa humana com HIV/AIDS a partir de sua raiz: suscitar sua confiança em Deus, arrancá-la do isolamento e do desespero, libertá-la do pecado, devolvê-la ao seio do povo de Deus e abrir-lhe um futuro de vida ainda mais digno e saudável.

No cotidiano da Pastoral da AIDS da Arquidiocese de Curitiba e do Grupo de Adesão ao Tratamento do HIV/AIDS do Hospital de Clínicas do Paraná, observa-se que, após o conhecimento do diagnóstico, as pessoas atravessam um "grande deserto", que envolve revoltas, tentativas 
de suicídio e sentimento de culpa, e acabam por desembocar em grandes necessidades espirituais. No caso de pessoas que já foram membros de alguma igreja ou movimento religioso, observa-se uma busca expressiva de Deus.

Para fundamentar nossa concepção teológica em tempos de HIV/ AIDS, buscamos como fundamento a imagem joanina de Deus. Em João, o conceito teológico central é a atuação do Pai no Filho. A unidade do Pai e do Filho é a base da Teologia e da Cristologia joanina (Jo 10,30). "O Evangelho de João não anuncia um Deus novo, mas sim Deus de um novo modo. Trata-se de um Deus único, vivo e verdadeiro (Jo 6,57), que enviou seu filho por amor ao mundo para salvar as pessoas que creem (Jo 3,16s). [...] Ninguém viu esse Deus invisível e transcendente, exceto o Filho que traz agora as boas novas do Pai (1 Jo 4,12a; Jo 1,18; 5,37; 6,46)".

No Evangelho de João, o tratamento e a predicação proeminente de Deus é Pai. Embora fosse um tratamento raro no Antigo Testamento, é uma denominação e um tratamento familiar de Deus nos escritos do judaísmo antigo. Em João (5, 25.26; 6.57), o Pai é o portador da vida e concede ao Filho poder sobre a vida. O Pai coloca os crentes nas mãos do Filho (Jo 6, 37.44.65), pois tudo o que o Pai tem pertence ao Filho (Jo, 16,15). No âmbito da imagética joanina da família, os crentes aparecem como “crianças de Deus". Eles são "gerados por Deus" (1 Jo 2, 29; 3,9; 4,7; Jo 1,$13 ; 3,3$ ss). A nova geração do ser humano realiza-se na fé pela força do espírito no batismo (Jo 3, 3.5). O status particular dos crentes em relação do Pai e do Filho expressa-se na designação de "irmãos" (3 Jo 3,5,10; Jo 20,17; 21, 23) e de "amigos" (3 Jo 15; Jo 11, 11; 15, 14s). Os discípulos não são estranhos ou servos, mas irmãos e amigos de Jesus porque cumprem a vontade do Pai. A base da unidade da Teologia joanina é a unidade de natureza, revelação e atuação entre o Pai e o Filho (Jo 1,1; 17, 20-22). Em João 10,30 lemos: “Eu e o Pai somos um”. Para Schnelle (2010, p. 875),

o centro da teologia joanina é a encarnação de Jesus Cristo, o Filho Preexistente de Deus. Atrás de Jesus está o próprio Deus, nisso reside a razão mais profunda para a verdade da pretensão de Jesus. Sua atuação fundamenta-se abrangentemente na unidade com o Pai, e unicamente dessa unidade, ele adquire sua dignidade singular [...]. 
A preexistência visa à encarnação, pois, em Jesus de Nazaré, Deus vai ao encontro do mundo humano à medida que Ele quer se revelar e operar em prol da salvação do mundo. A preexistência e a encarnação respondem, do mesmo modo, a antiga pergunta religioso-filosófica sobre como e onde aconteceu o encontro entre a transcendência e a imanência. Dessa maneira, o prólogo do Evangelho de João abarca em si o significado de glória e dignidade do ser humano. É uma história que descreve como "Deus se volta para os seres humanos, pois dirigir a palavra para alguém significa voltar-se para essa pessoa: no Logos Jesus Cristo, Deus volta-se para os seres humanos”. Em João, é Deus quem estabelece a existência, o tempo e a ordem.

Deus sai de si mesmo como o que fala; sua palavra, porém, vai muito além da mera comunicação: é a palavra que cria vida. Deus não pode ser pensado sem sua palavra; na palavra, ele não só se comunica, mas revela sua natureza e permite que os seres humanos participem dela na fé no Logos Jesus Cristo, de modo que o Logos é igualmente formação, interpretação e comunicação do divino (SCHNELLE, 2010, p. 882).

O estado de pertença a Deus desconhece limitações temporais e materiais; é abrangente e total porque tem sua origem antes do tempo e do cosmos. Em Jo (1, 14.17), Jesus Cristo aparece como o lugar da graça e da verdade de Deus. A liberdade é, portanto, o efeito imediato da experiência da verdade que os crentes percebem: "E conhecereis a verdade, e a verdade vos libertará" (Jo 8,32). A dimensão pessoal do conceito joanino de verdade manifesta-se explicitamente em Jo (14,6): "Eu sou o caminho, a verdade e a vida; ninguém chega ao Pai a não ser por mim”. Jesus é o caminho, porque ele mesmo é a verdade e proporciona a vida.

É essa "reivindicação interior de ser absoluto", que crê e confessa Jesus como o caminho único e exclusivo para Deus, que dá sentido pleno para o cristão. É a possibilidade de reconhecer Deus e de chegar a Deus, como a meta de toda vida e busca religiosa, que move o ser humano para a plenitude e a perfeição. Esse poder de criação e de vida manifesta-se em João na grandeza dos milagres (Jo 2, 1-11), nas curas (Jo 4, 46-54), na alimentação milagrosa de cinco mil pessoas (Jo 6, 1-15), na ressurreição de Lázaro (Jo 11, 1-44). É nos milagres e em outros contextos que se destaca 
a humanidade de Jesus. Trata-se, portanto, de uma encarnação permanente: a atuação de Jesus abraça o tempo e o espaço. "O batismo e a Eucaristia testemunham a permanente presença salvífica do revelador que vem do céu e se voltou para os seres humanos" (SCHNELLE, 2010, p. 887).

Assim, podem-se elucidar novos caminhos de enfrentamento e de cuidado que valorize o vivido, a singularidade e a dimensão existencial do soropositivo e suas implicações no "mundo da vida". É possível, em nossas práticas científicas e teológicas, caminhar no sentido de uma ascensão ao ser, acompanhar o percurso que se realiza nos desdobramentos dos sentidos de ser em direção ao ser Último: Deus (STEIN, 1998).

\section{Conclusão}

O progresso científico vem colocando nas mãos da humanidade um poder cada vez maior de produzir, modificar, selecionar e direcionar. Os novos recursos geram mudanças rápidas e drásticas, mas aumentam igualmente as possibilidades de sobrevivência e de qualidade de vida das pessoas.

A inserção da pessoa com HIV/AIDS em um programa de prevenção e/ou de tratamento vai além do fato de ela ser soropositiva. O cuidado e o descuido apresentam-se como possibilidades de dignificação ou de negativização da sorologia. Se, por um lado, a experiência de viver e conviver com HIV/AIDS ocasiona manifestações de ordem biofisiológicas com implicações sociais, por outro, leva à compreensão da constituição do mundo vivido do soropositivo e/ou do mundo que não se concretizou.

Dar visibilidade, revisitar, revelar o "rosto escondido" e "seu silêncio", além de se constituir uma tarefa para a ética, é a missão da Teo-

logia. É o rosto enfermo, violentado, estigmatizado e discriminado que ordena e indica os caminhos para a Teologia. Portanto, o pensar o rosto escondido do outro ultrapassa a dimensão perceptiva, isso porque o modo de aparição do rosto é diferente do modo de aparição das coisas (LEVINAS, 1988).

Nesse sentido, consideramos fundamental para uma teologia em tempos de HIV/AIDS um olhar humano voltado para o olhar suplicante 
do outro (soropositivo) que apela para ser acolhido e desvelado. Esse é o sentido que queremos imprimir à Teologia prática. Deus vem habitar na acolhida do outro, na vivência concreta do amor entre os homens. E na experiência cristã, um dos efeitos propiciado pelo amor, pela caridade, é a misericórdia. É a atitude que Deus espera de cada um de nós. A compaixão e o amor gratuito pelo próximo (Lc 10, 29).

\section{Referências}

ALES BELLO, A. A fenomenologia do ser humano. Tradução de Antonio Angonese. Bauru, São Paulo: EDUSC, 2000.

ALVES, R. $O$ enigma da religião. Campinas: Papirus, 1984.

BAYÉS, R. Psiconeuroinmunologia, salud y enfermedad. Cuadernos de Medicina Psicosomática, v. 30, p. 28-34, 1994.

BOFF, L. Saber cuidar: ética do humano. Compaixão pela terra. Petrópolis: Vozes, 1999.

BRASIL. MINISTÉRIO DA SÁUDE. Boletim Epidemiológico - AIDS/DST. ano III, n. $1,01^{\text {a }}$ a $26^{\text {a }}$ semanas epidemiológicas - janeiro a julho de 2006. Brasília. Disponível em: <http://www.aids.gov.br/taxonomy/term/boletimepidemiologico>. Acesso em: 20 jun. 2011.

BRASIL. MINISTÉRIO DA SÁUDE. Boletim Epidemiológico - AIDS/DST, v. 5, n. 1, 2008. Brasília. Disponível em: <http://www.aids.gov.br/sites/default/files/ Boletim2008_versao1_6.pdf $>$. Acesso em: 20 jun. 2011.

BRASIL. MINISTÉRIO DA SAÚDE. MS divulga retrato do comportamento sexual do brasileiro. Notícias, 18 jun. 2009. Disponível em: <http://portal.saude. gov.br/portal/aplicacoes/noticias/default.cfm?pg=dspDetalheNoticia\&id_ area $=124 \& C O \_$NOTICIA=10326 $>$. Acesso em: 2 jun. 2011.

BRASIL. MINISTÉRIO DA SAÚDE. Secretaria de Vigilância em Saúde - Departamento de DST. AIDS e Hepatites Virais. Boletim Epidemiológico, AIDS e DST, Brasília, v. 7, n. 1 p. 6, 2010a. 
BRASIL. MINISTÉRIO DA SAÚDE. semanas epidemiológicas janeiro a junho. Boletim Epidemiológico - AIDS e DST, v. 7, n. 1, 2010b. Brasília, Disponível em: <http://www.aids.gov.br/pagina/aids-no-brasil>. Acesso em: 20 jun. 2011.

BRASIL. MINISTÉRIO DA SAÚDE. Secretaria de Vigilância em Saúde. 2010. Disponível em: < portal.saude.gov.br/portal/arquivos/pdf/clipping_29_09_2010. pdf $>$. Acesso em: 15 jun. 2011.

CALVETTI, P. Ü. Fatores biopsicossociais preditivos para a adesão e qualidade de vida em pessoas que vivem com HIV/AIDS bem-sucedidas no tratamento de saúde. 2010. 73 f. Tese (Doutorado em Psicologia) - Pontifícia Universidade Católica do Rio Grande do Sul, Porto Alegre, 2010.

CURITIBA. Agência de Notícias da Prefeitura de Curitiba. Blitz de prevenção à AIDS e dengue na Rodoviária, dia 4 mar. 2011. Disponível em: < http://www. curitiba.pr.gov.br/noticias/blitz-de-prevencao-a-aids-e-dengue-na-rodoviaria-nesta-sexta/22093>. Acesso em: 20 jun. 2011.

FARIA, A.; VAZ, N. M. AIDS: sintomas de uma crise médica. In: FARIA, A.; VAZ, N. M. AIDS: ética, medicina e biotecnologia. Rio de Janeiro: Hucitec; Abrasco, 1995.

GEERTZ, C. A interpretação das culturas. Rio de Janeiro: LTC, 1998.

GLOBO. UNAIDS e o cenário da AIDS/HIV no Brasil. Sexta-feira, 17 de junho de 2011. Disponível em: <http://alcymartins.blogspot.com/2011/06/unaids-e-o-cenario-da-aidshiv-no-brasil_17.html>. Acesso em: 24 jun. 2011.

HEIDEGGER, M. Ser e tempo. Petrópolis: Vozes, 1989.

KERN, F. A. Redes de apoio no contexto da AIDS: um retorno para a vida. Porto Alegre: EDIPUCRS, 2004.

LEVINAS, E. Totalidade e infinito. Tradução de José Pinto Ribeiro. Lisboa: Edições 70, 1988.

MADEIRA, M. C. A confiança afrontada: representações sociais da AIDS para jovens. In: MADEIRA, M.; JODELET, D. (Org.). AIDS e representações sociais: à busca de sentidos. Natal: EDUFRN, 1998. p. 47-72. 
MARTIN, D. Mulheres e AIDS: uma abordagem antropológica. Revista USP, n. 33, p. 89-101, 1997.

MERLEAU-PONTY, M. Merleau-Ponty na Sorbonne: resumo de cursos psicossociologia e filosofia. Campinas: Papirus, 1990.

MONTEIRO, S. S. AIDS e proteção: a visão de jovens de um bairro popular. Revista de Estudos Feministas, ano 7, p. 72-88, 1999a.

MONTEIRO, S. S. AIDS, sexualidade e gênero: a lógica da proteção entre jovens de um Bairro Popular Carioca. 1999. 186 f. Tese (Doutorado em Saúde Pública) - Escola Nacional de Saúde Pública, FIOCRUZ, Rio de Janeiro, 1999b.

MOTTA, A. B. Chegando pra idade. In: LINS DE BARROS, M. M. (Org.). Velhice ou Terceira Idade? Estudos antropológicos sobre identidade, memória e política. Rio de Janeiro: Fundação Getúlio Vargas, 2003. p. 223-235.

PAGOLA, J. A. Jesus: aproximação histórica. Tradução de Gentil Avelino Titton. Petrópolis: Vozes, 2010.

PARANÁ. Secretaria de Estado da Saúde. Plano de enfrentamento da feminização da epidemia da AIDS no Paraná. Curitiba: SESA, 2009.

PAIVA, V. O simbolismo da AIDS, alteridade e cidadania. In: PAIVA, V. (Org.). Em tempos de AIDS: viva a vida: sexo seguro, prevenção, drogas, adolescentes, mulheres, apoio psicológico aos portadores. São Paulo: Summus, 1992. p. 53-62.

PARKER, R. Na contramão da AIDS: sexualidade, intervenção, política. Rio de Janeiro: ABIA; Editora 34, 2000.

PARKER, R.; HERDT, G.; CARBALLO, M. Cultura sexual, transmissão do HIV e pesquisas sobre AIDS. In: CZERESNIA, D. et al. (Org.). AIDS: pesquisa social e educação. São Paulo: Hucitec; Rio de Janeiro: ABRASCO, 1995. p. 17-45.

PERETTI, C. L'empatia nel rapporto interpersonale in Edith Edith

Stein. Pontificium Athenaeum Antonianum. Institutum Superius Scientiarum Religiosarum, "Redemptor Hominis". 1997. Dissertatio (Gradum Magisterii) Pontificium Athenaeum Antonianum, Romae, 1997. 
PERETTI, C. Edith Stein e as questões de gênero: perspectiva fenomenológica e teológica. 2009. 302 f. Tese (Doutorado em Teologia) - Escola Superior de Teologia, EST, São Leopoldo, 2009.

SCHNELLE, U. Teologia do novo testamento. São Paulo: Academia Cristã; Paulus, 2010.

SILVA, M. A. M. O. Velhos de rua no Brasil: a morte silenciosa. A Terceira Idade, São Paulo, v. 9, n. 12, p. 35-43, 1996.

STEIN, E. Psicologia e scienze dello spirito: contributi per una fondazione filosófica. $2^{a}$ ed. Traduzione A. M. Pezzella. Roma: Cittá Nuova, 1999.

TURA, L. F. R. A AIDS, o preservativo e a prevenção". In: JORNADA INTERNACIONAL SOBRE REPRESENTAÇÕES SOCIAIS: TEORIA E CAMPO DE APLICAÇÃO, 1., 1998, Natal. Anais... Natal: Jornada Internacional sobre Representações Sociais: Teoria e Campo de Aplicação, 1998. p. 38.

ULLA, S.; REMOR, E. A. Psiconeuroimunologia e infecção por HIV: realidade ou Fiç̧ão? Psicologia Reflexão e Crítica, v. 15, n. 1, p. 113-119, 2002.

Recebido: 30/05/2011

Received: 05/30/2011

Aprovado: 06/08/2011

Approved: 08/06/2011 